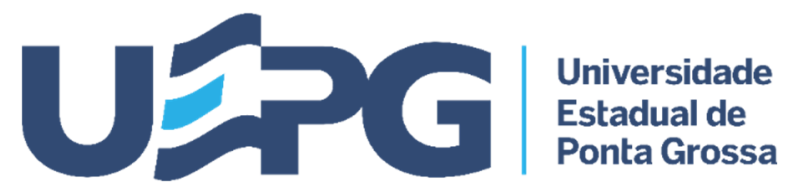

Revista Teias do Conhecimento

Ano 1, Numero 1, 2021

\title{
A EDUCAÇÃO NO PROCESSO DE RESSOCIALIZAÇÃO DO APENADO
}

\author{
http://doi.org/10.5212/RevTeiasConhecimento.v111.20210070
}
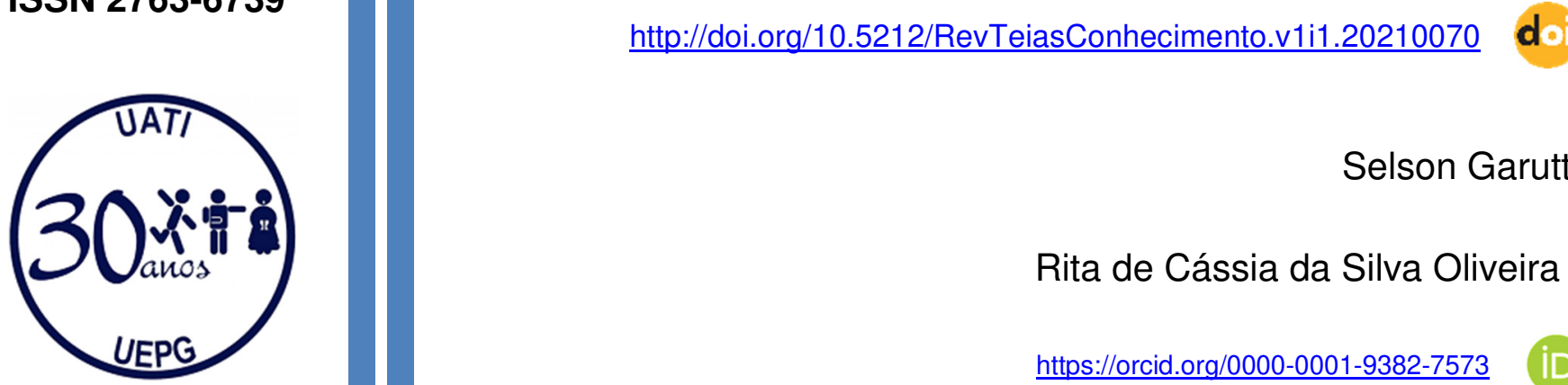

Selson Garutti

Rita de Cássia da Silva Oliveira **

https://orcid.org/0000-0001-9382-7573

http://lattes.cnpq.br/0396336269506743

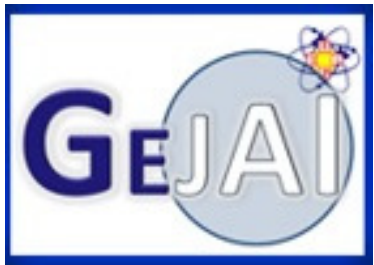

RESUMO: Este trabalho apresenta um estudo qualiquantitativo exploratório que tem por objetivo analisar a evolução escolar dos alunos internos da Penitenciaria Estadual de Maringá (PEM). No que diz respeito às discussões do processo educacional constituído no interior da PEM sobre qual deva ser o papel educativo na ressocialização dos apenados entre os anos de 2006 a 2010, as análises foram feitas sob uma perspectiva histórica dialética e conclui-se que a elevação do nível escolar é essencial para que todos os apenados consigam melhores oportunidades de trabalho e inserção social após o cumprimento de sua pena.

PALAVRAS-CHAVE: Educação; Penitenciaria; Ressocialização.

\section{* In memorian}

** Pós-doutora pela Universidad de Santiago de Compostela (Espanha) e Professora do Programa de Pós-Graduação em Educação (Mestrado e Doutorado) da Universidade Estadual de Ponta Grossa (UEPG), 曾 soliveira@uepg.br 


\title{
EDUCATION IN THE PROCESS OF RESOCIALIZATION OF THE PENDANT
}

\begin{abstract}
This work presents an exploratory qualiquantitative study that aims to analyze the school evolution of inmates at the State Penitentiary of Maringá (PEM). With regard to the discussions of the educational process constituted within the PEM about what should be the educational role in the resocialization of inmates between the years 2006 to 2010, the analyzes were carried out under a dialectical historical perspective and it was concluded that the increase in the school level is essential for all inmates to get better work opportunities and social inclusion after serving their sentence.
\end{abstract}

KEYWORDS: Education; Penitentiary; Resocialization.

\section{EDUCACIÓN EN EL PROCESO DE RESOCIALIZACIÓN DEL COLGANTE}

RESUMEN: Este trabajo presenta un estudio exploratorio cualitativo que tiene como objetivo analizar la evolución escolar de los internos de la Penitenciaría Estatal de Maringá (PEM). En cuanto a las discusiones del proceso educativo constituido dentro del PEM sobre cuál debe ser el rol educativo en la resocialización de los internos entre los años 2006 a 2010, los análisis se realizaron bajo una perspectiva histórica dialéctica y se concluyó que el incremento de El nivel escolar es fundamental para que todos los reclusos obtengan mejores oportunidades laborales e inclusión social después de cumplir su condena.

PALABRAS CLAVE: Educación; Penitenciario; Resocialización. 


\section{INTRODUÇÃO}

O sistema prisional brasileiro vem sofrendo, nos últimos anos, um aumento considerável no número de atendimentos. A configuração da prisão como espaço de encarceramento dos desviantes e punição de seus crimes tem ganhado considerável espaço na concepção da sociedade moderna capitalista, além de espaço disciplinar de caráter penal constituído historicamente. Essa política de encarceramento massivo reflete, pois, as consequências de uma sociedade capitalista que marginaliza grande parte da população em que uma menor parte acumula riquezas, enquanto a outra maior acumula miséria, sendo essa discrepância que gera desesperança e violência. Assim, este trabalho tem por objetivo analisar a evolução escolar dos alunos internos da Penitenciaria Estadual de Maringá (PEM).

\section{MATERIAL E MÉTODO}

TIPO DE ESTUDO: pesquisa de natureza básica de abordagem qualitativa, caracterizada como pesquisa exploratória bibliográfica e de estudo de caso por se tratar de um estudo profundo sobre um evento específico cuja investigação busca focalizar os aspectos em uma realidade maior sobre a ressocialização por meio da oferta de educação para jovens e adultos em situação de privação de liberdade nos estabelecimentos penais.

PLANO DE TRABALHO: Pelo resgate bibliográfico verifica-se a necessidade da adoção de uma sequência metodológica, tanto na fase de levantamento quanto na de análise e interpretação dos dados. Nesta metodologia os dados devem ser entendidos como sendo complementares e que se retroalimentam no processo de pesquisa. Assim, essa pesquisa se constitui a partir do referencial teórico fornecido pelo Professor Antônio Carlos Gomes da Costa², por se tratar de um dos especialistas que mais discute no Brasil a questão educacional para jovens e adultos em situação de

\footnotetext{
2 Pedagogo. Mineiro. Trabalhou na FEBEM, em Minas Gerais, e na Organização Internacional do Trabalho (OIT), em Genebra, Suíça. Fez parte da equipe de peritos do Comitê dos Direitos da Criança, da Organização das Nações Unidas (ONU) e da equipe que criou o Estatuto da Criança e do Adolescente (ECA).
} 


\section{A Educação no processo de ressocialização do apenado}

privação de liberdade nos estabelecimentos penais.

PROPOSTA DE ANÁLISE: Esta sistematização de proposta segue, basicamente, três etapas: Pré-análise: consiste na seleção e organização do material documental e bibliográfico; Descrição analítica: consiste no processo de análise profunda dos documentos e bibliografia, tomando como base as hipóteses e referenciais teóricos. Neste momento é que se criam os temas de estudo e as tramas de relações, podendose fazer a sua decodificação, classificação e/ou categorização; Interpretação referencial: consiste em um momento de compreensão mais ampla das inferências e relações construídas entre as bases documentais. É neste momento que, a partir dos dados empíricos e informações coletadas, estabelece-se a compreensão das relações entre o objeto de análise e seu contexto mais amplo, chegando às reflexões que constituem a verificação das hipóteses anteriormente conjeturadas em vista das estruturas e relações propostas:

a) Levantamento das fontes; b) Leitura da bibliografia e dos documentos; c) Análise dos dados e Elaboração dos resultados finais;

\section{RESULTADOS E DISCUSSÃO}

Sendo que a Penitenciária comporta 360 internos, 200 a 250 frequentam a escola, a média anual destes na escola geralmente oscilou entre $60 \%$ a $70 \%$ dependendo do ano: 


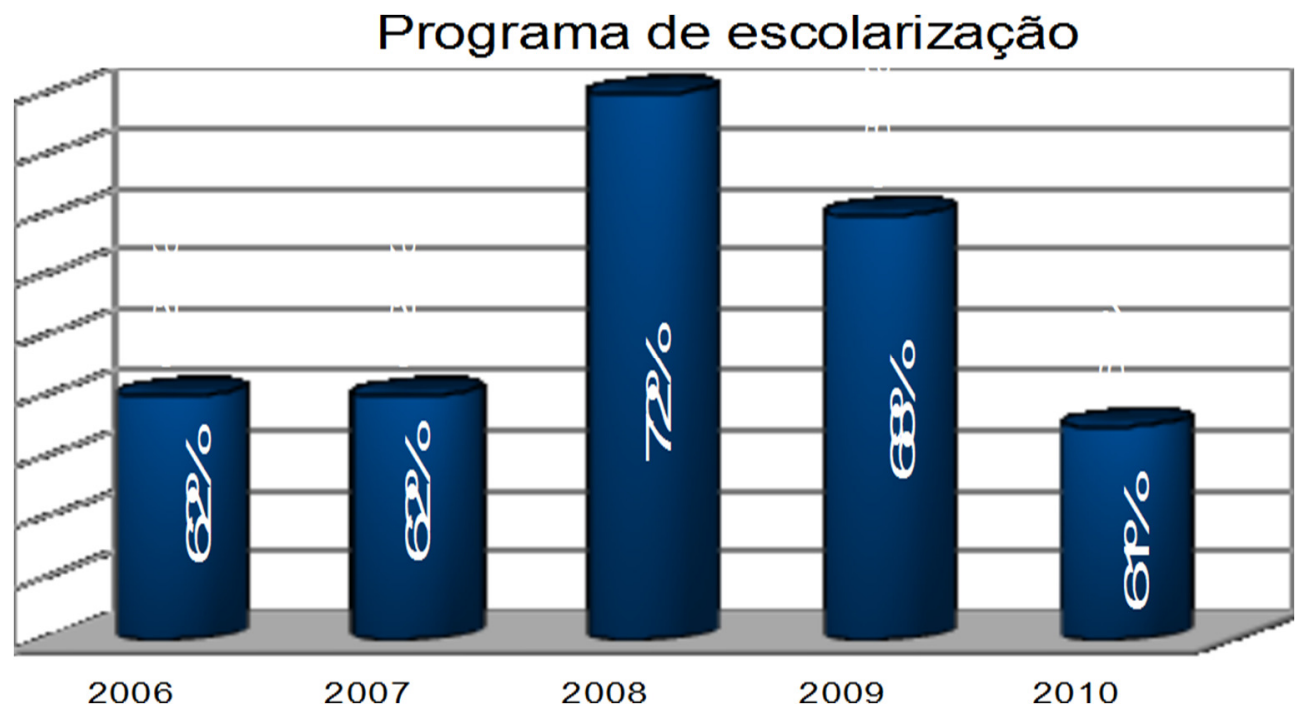

\begin{tabular}{|c|c|c|c|c|}
\hline \multicolumn{5}{|c|}{ Quadro Comparativo da Movimentação Escolar de 2006 } \\
\hline Alfabetização & Fase I & Fase II & Ensino Médio & Total \\
\hline 27 & 45 & 103 & 48 & 223 \\
\hline
\end{tabular}

Fonte: Dados coletados no arquivo do Centro de Estudos Supletivos Professora Tomires Moreira de Carvalho. 


\section{Programa de escolarização 2006}

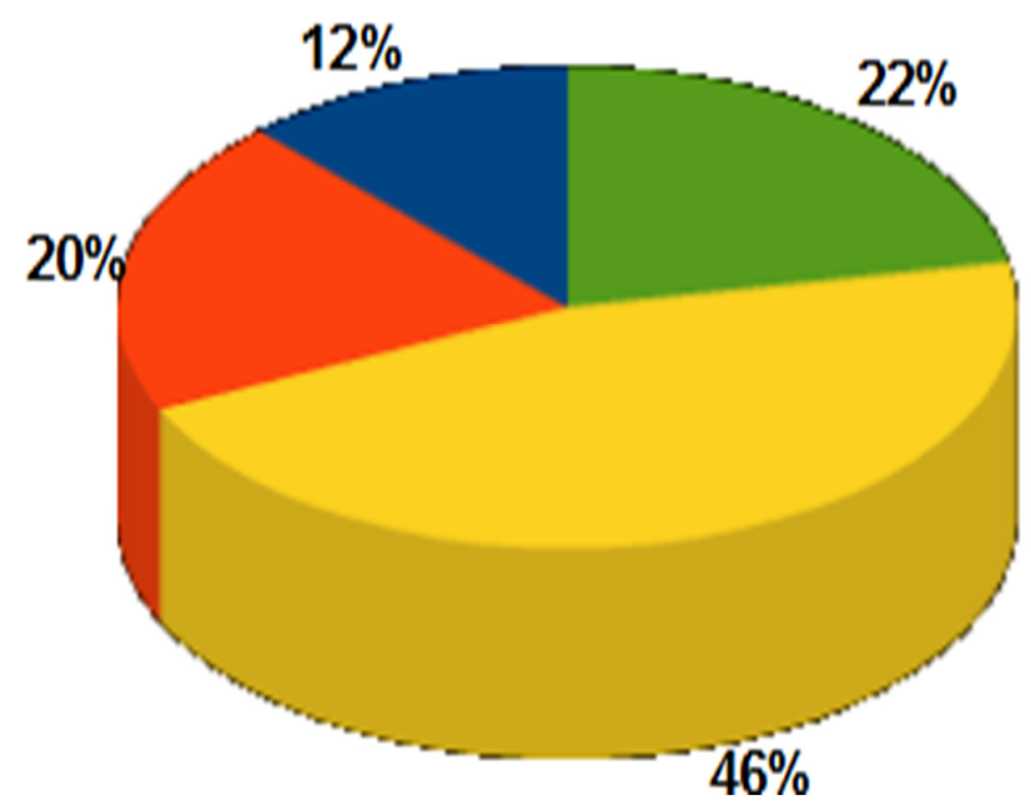

Alfabet.

Fase I

Fase II

Médio

\begin{tabular}{|c|c|c|c|c|}
\hline \multicolumn{6}{|c|}{ Quadro Comparativo da Movimentação Escolar de 2007} \\
\hline Alfabetização & Fase I & Fase II & Ensino Médio & Total \\
\hline Não & 68 & 108 & 49 & 225 \\
\hline
\end{tabular}

Fonte: Dados coletados no arquivo do Centro de Estudos Supletivos Professora Tomires Moreira de Carvalho.

\begin{tabular}{|c|c|c|c|c|}
\hline \multicolumn{5}{|c|}{ Quadro Comparativo da Movimentação Escolar de 2008 } \\
\hline Alfabetização & Fase I & Fase II & Ensino Médio & Total \\
\hline 40 & 40 & 107 & 74 & 261 \\
\hline
\end{tabular}

Fonte: Dados coletados no arquivo do Centro de Estudos Supletivos Professora Tomires Moreira de Carvalho. 


\section{Programa de Escolarização 2008}

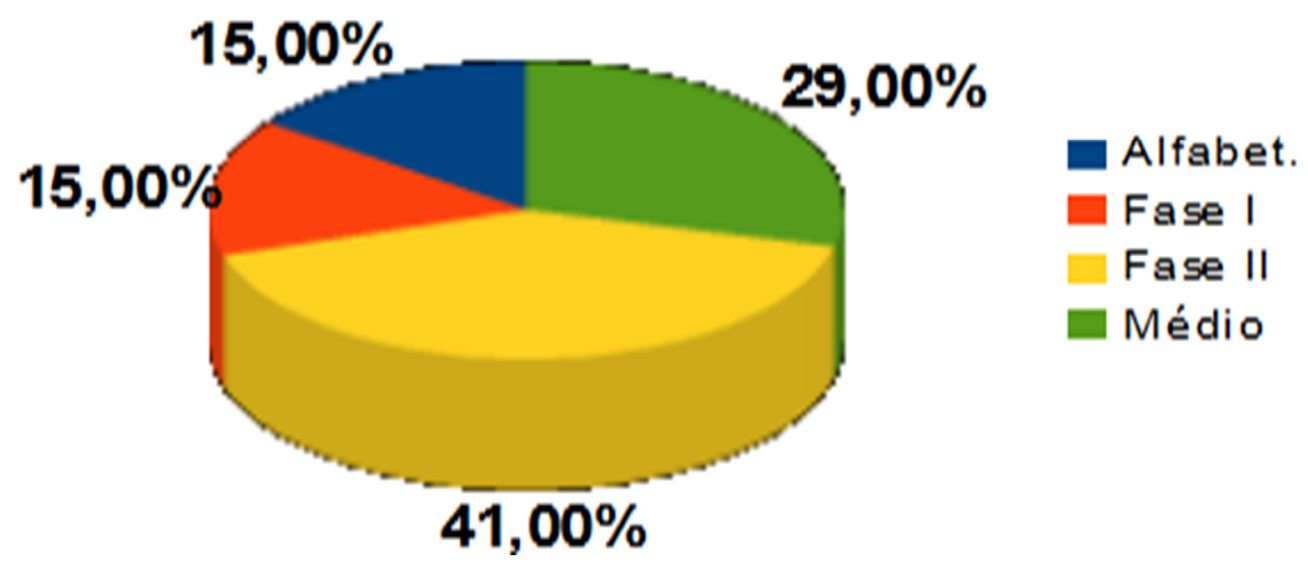

\section{Programa de Escolanização 2007}

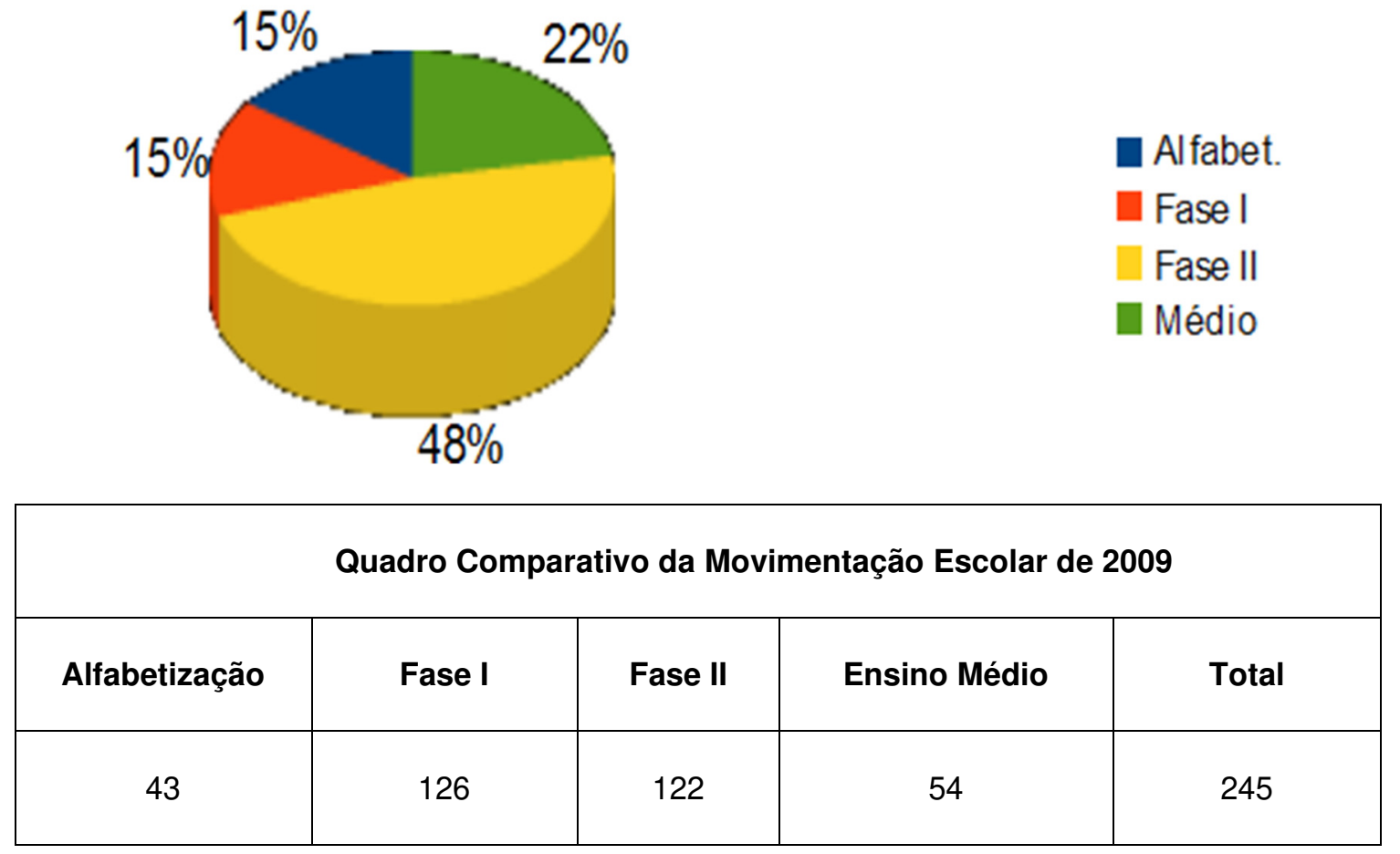

Fonte: Dados coletados no arquivo do Centro de Estudos Supletivos Professora Tomires Moreira de Carvalho. 
A Educação no processo de ressocialização do apenado

Selson Garutti e Rita de Cássia da Silva Oliveira

\begin{tabular}{|c|c|c|c|c|}
\hline \multicolumn{5}{|c|}{ Quadro Comparativo da Movimentação Escolar de 2010} \\
\hline Alfabetização & Fase I & Fase II & Ensino Médio & Total \\
\hline 27 & 29 & 122 & 42 & 220 \\
\hline
\end{tabular}

Fonte: Dados coletados no arquivo do Centro de Estudos Supletivos Professora Tomires Moreira de Carvalho.

\section{Programa de Escolarização 2010}

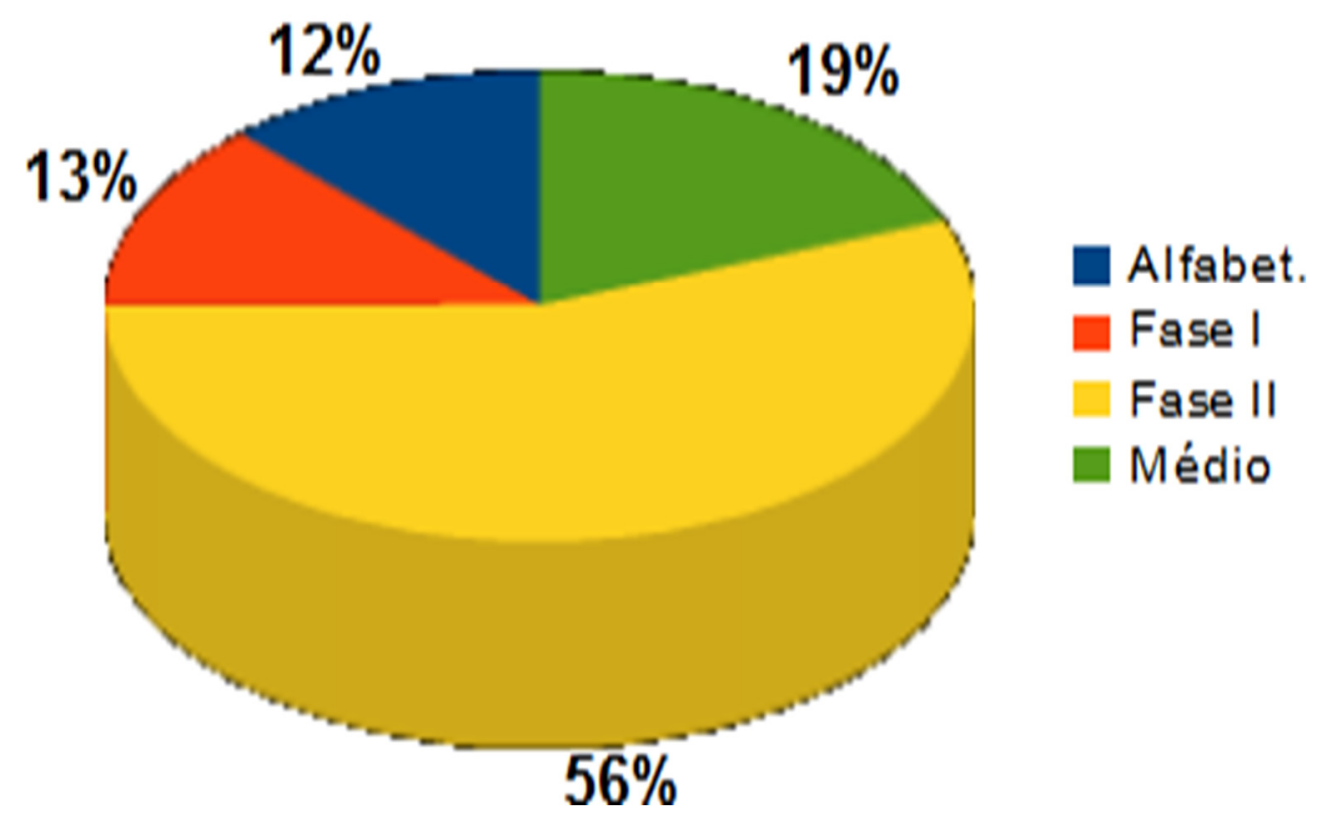




\section{Programa de Escolarização 2009}

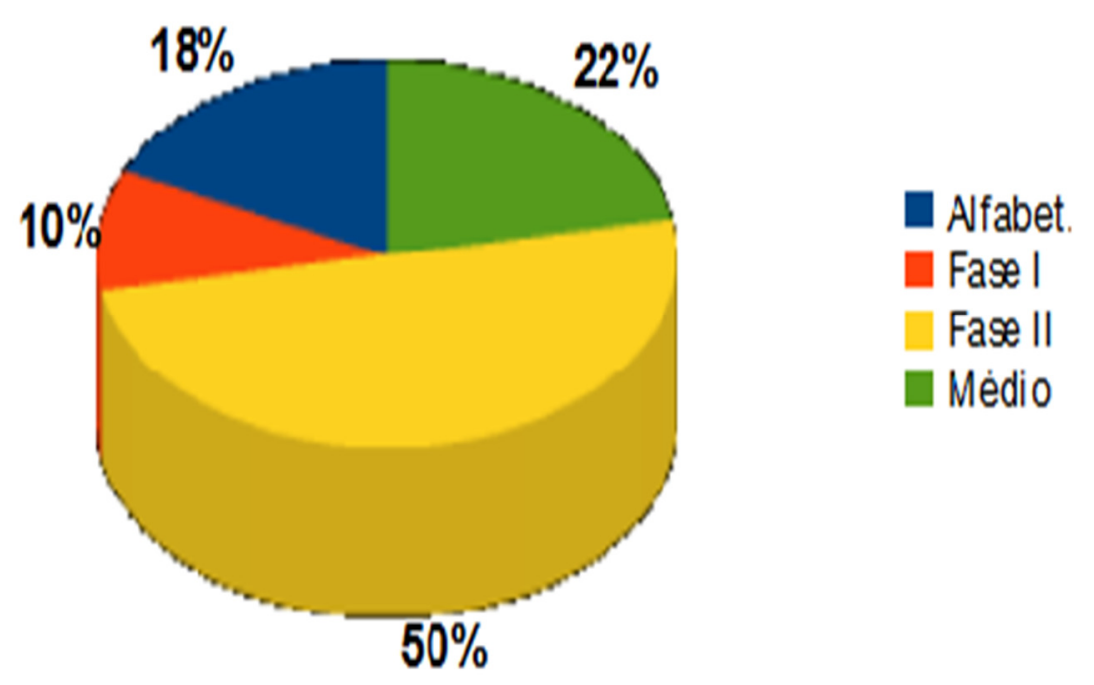

Observando os dados, pode-se constatar a baixa escolaridade da população carcerária que se encontra cumprindo pena na PEM. Realidade que não é exclusividade da PEM. A realidade educacional dos presos que cumprem pena no Presídio Estadual de Maringá (PEM) reflete a situação das demais instituições prisionais do estado e do país. Mesmo que o dado estatístico sobre educação penitenciaria sejam insuficientes para estabelecer um diagnóstico sobre a situação em todo o país, os dados da PEM servem como ilustração da realidade brasileira. A baixa escolaridade da população carcerária nos faz pensar sobre qual deva ser o real papel da educação e qual sua efetividade no processo de ressocialização? Levandose em conta que a escolarização dentro da penitenciária tem como finalidade a formação nos ensinos fundamental e médio das pessoas presas, constituindo assim, uma possível ressocialização do ponto de vista social e ético, a partir dos dados referendados, a educação influencia consideravelmente na vida profissional do encarcerado. A tríade de Educação, qualificação e trabalho são, portanto, os pilares da ressocialização. A elevação do nível escolar é essencial para que os penados consigam trabalho e inserção social após o cumprimento de sua pena. 


\section{A Educação no processo de ressocialização do apenado}

\section{CONCLUSÃO}

A abordagem do tema ressocialização, na perspectiva dos direitos humanos, tem como função trazer para o centro da discussão o redimensionamento das políticas públicas prisionais e, qual seja de fato o grau de efetivação na redução dos danos sociais causados. Não se trata de amainar os atos violentos cometidos pelos presos, mas é necessário considerar que uma real redução dos índices de violência só será concretizada na medida em que realmente houver uma maior integração e inserção social digna para esses sujeitos, apenas quando o sistema conseguir absorver suas necessidades tanto por educação, saúde, moradia, quanto por uma vida digna, ou seja, a concretização do sentimento de pertença social. Ainda existe um inenarrável fosso de discrepância entre pobres e ricos, sendo que os mais abastados não são penalizados, pois possuem recursos para sua defesa. A prisão torna-se uma instituição de criminalização da pobreza, pois quanto mais desprovidos de proventos, são condenados. 


\section{REFERÊNCIAS}

BRASIL. Estatuto da criança e do adolescente. 5ª ed. São Paulo: Saraiva, 1995.

BECCARIA. C. Dos Delitos e Das Penas. São Paulo: Martin Claret, 2004.

COSTA, Antônio Carlos Gomes Da. Socioeducação: Estrutura e Funcionamento da Comunidade Educativa. Brasília: Secretaria Especial de Direitos Humanos, 2006.

FOUCAULT, Michael. Vigiar e punir. Petrópolis: Vozes, 1991. FOUCAULT, Michael. Microfísica do poder. Rio de Janeiro: Graal, 1999.

GOFFMAN, E. Manicômios, prisões e conventos. São Paulo: Perspectiva, 1974.

GOMES NETO, Pedro Rates. A prisão e o sistema penitenciário: uma visão histórica. Canoas: Ulbra. 2000.

PERROT, M. Os excluídos da história: operários, mulheres e prisioneiros. 2. Edº. Rio de Janeiro: Paz e Terra, 1994. (Coleção: Oficinas da História, vol. 12). 


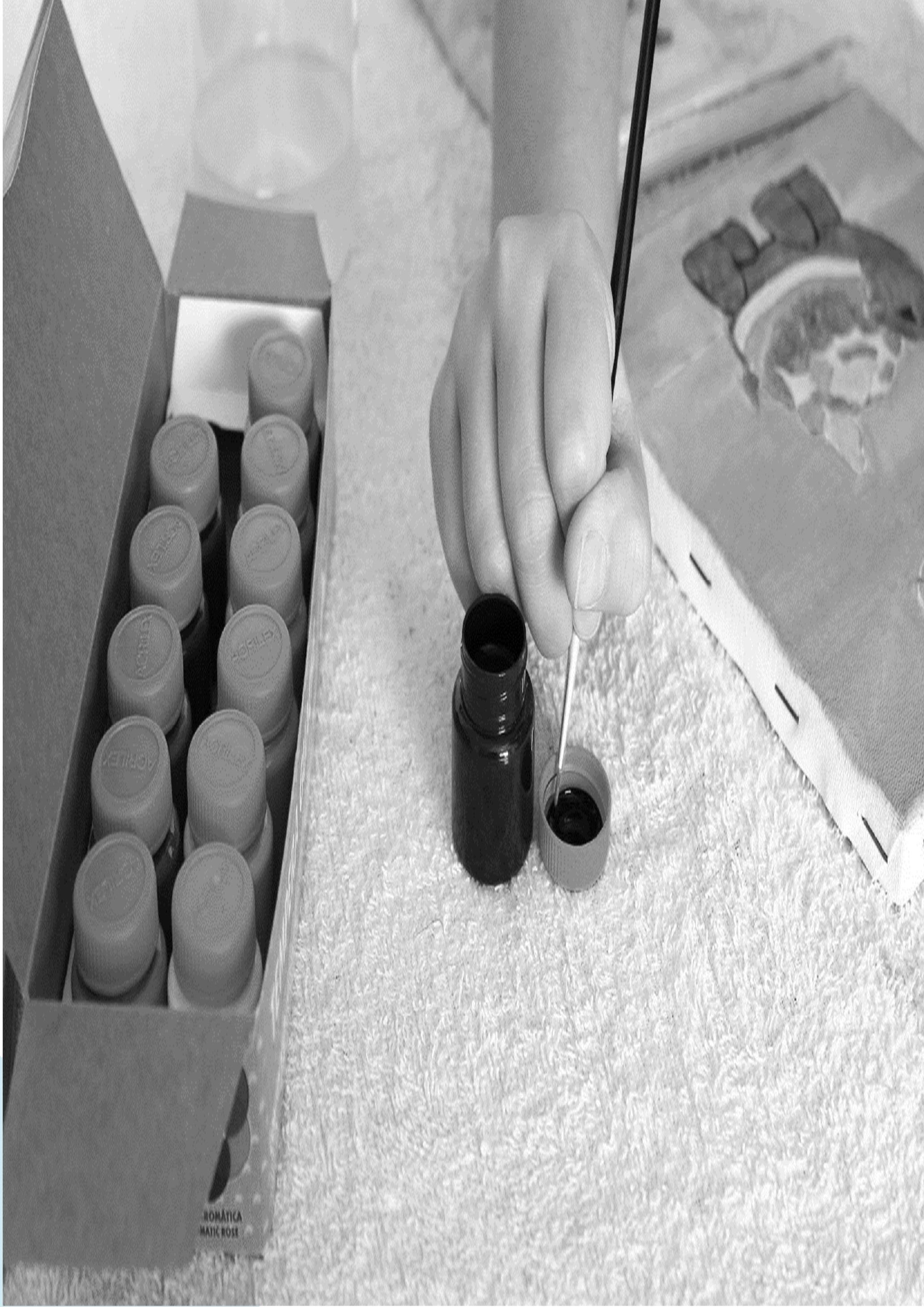

